\title{
Antimicrobial and Attractant Roles for Chemerin in the Oral Cavity during Inflammatory Gum Disease
}

\author{
Urszula Godlewska', Piotr Brzoza', Aneta Sroka², Pawel Majewski', Holger Jentsch ${ }^{3}$, \\ Martin Eckert', Sigrun Eick ${ }^{4}$, Jan Potempa ${ }^{2,5}$, Brian A. Zabel ${ }^{6}$ and Joanna Cichy ${ }^{1 *}$ \\ ${ }^{1}$ Faculty of Biochemistry, Biophysics and Biotechnology, Department of Immunology, Jagiellonian University, Kraków, Poland, \\ ${ }^{2}$ Faculty of Biochemistry, Biophysics and Biotechnology, Department of Microbiology, Jagiellonian University, Kraków, \\ Poland, ${ }^{3}$ Centre for Periodontology, Department of Cariology, Endodontology and Periodontology, University Hospital of \\ Leipzig, Leipzig, Germany, ${ }^{4}$ Department of Periodontology, School of Dental Medicine, University of Bern, Bern, Switzerland, \\ ${ }^{5}$ Department of Oral Immunology and Infectious Diseases, University of Louisville School of Dentistry, Louisville, KY, USA, \\ ${ }^{6}$ Palo Alto Veterans Institute for Research, VA Palo Alto Health Care System, Palo Alto, CA, USA
}

\section{OPEN ACCESS}

Edited by:

Raffaella Bonecchi, Università degli Studi di Milano, Italy

Reviewed by:

Paul Proost,

K.U.Leuven, Belgium

Tiziana Musso,

University of Turin, Italy

*Correspondence: Joanna Cichy joanna.cichy@uj.edu.pl

Specialty section: This article was submitted to Cytokines and Soluble Mediators in Immunity,

a section of the journal

Frontiers in Immunology

Received: 23 January 2017 Accepted: 13 March 2017

Published: 29 March 2017

Citation:

Godlewska U, Brzoza P, Sroka A, Majewski P, Jentsch H, Eckert $M$, Eick S, Potempa J, Zabel BA and Cichy J (2017) Antimicrobial and

Attractant Roles for Chemerin in the Oral Cavity during Inflammatory Gum Disease.

Front. Immunol. 8:353. doi: 10.3389/fimmu.2017.00353
Periodontal inflammation is one of the most common chronic inflammatory conditions in humans. Despite recent advances in identifying and characterizing oral microbiota dysbiosis in the pathogenesis of gum disease, just how host factors maintain a healthy homeostatic oral microbial community or prevent the development of a pathogenic oral microbiota remains poorly understood. An important determinant of microbiota fate is local antimicrobial proteins. Here, we report that chemoattractant protein chemerin, which we recently identified as a potent endogenous antimicrobial agent in body barriers such as the skin, is present in the oral cavity under homeostatic and inflammatory conditions. Chemerin and a chemerin-derived antimicrobial peptide are bactericidal against select bacteria strategically positioned in dental biofilm. Gingival crevicular samples from patients with gingivitis but not periodontitis contain abundant bioactive chemerin capable of inducing CMKLR1-dependent leukocyte migration. Gingipains secreted by the periodontopathogen $P$. gingivalis inactivate chemerin. Together, these data suggest that as an antimicrobial agent and leukocyte chemoattractant, chemerin likely contributes to antimicrobial immune defense in the oral cavity.

Keywords: chemerin, antimicrobial peptides, chemoattractant, inflammation mediators, microbiota, oral cavity

\section{INTRODUCTION}

Chemerin is a chemoattractant protein implicated in recruitment of dendritic cells (DCs), macrophages, and NK cells to sites of inflammation (1). These immune cells express the G-protein-coupled signaling receptor CMKLR1, which mediates cell chemotactic responses to bioactive chemerin (2, $3)$. Chemerin circulates as an inactive isoform (chemS163) and needs to be proteolytically processed to display chemotactic potential. Bioactive chemerin lacking six amino acids in the C-terminus (chemS157) has been isolated from body fluids (1), and various serine and cysteine proteases of host and microbial origin can generate active chemerin by C-terminal processing in vitro (4-6). However, proteases can also inactivate or degrade the attractant and thus limit the extent of chemerin activity (1). Chemerin is broadly expressed in numerous anatomic sites, including liver and fat tissues as well as by epithelial cells in the skin epidermis $(7-10)$, intestinal epithelium $(8,11)$, and pulmonary 
airways $(8,12)$. The strategic positioning of chemerin at the hostenvironment interface suggests a role in antimicrobial defense.

We recently demonstrated that human recombinant chemerin as well as endogenous chemerin secreted by primary human keratinocytes in organ cultures significantly inhibited growth of skin bacteria $(6,9)$. As is the case for chemoattractant activity, the inhibitory C-terminal peptide present in the chemerin holoprotein chem163S must be removed for full antibacterial effects. An internal 20-amino acid peptide $\mathrm{V}^{66}-\mathrm{P}^{85}$ embodies most of the antimicrobial activity of active chemerin, and is comparable in potency to other antimicrobial peptides (AMPs) (9). Chemerin was recently reported to be present in the oral cavity, and the levels of chemerin in saliva and gingival crevicular fluid were increased in patients suffering from periodontitis $(13,14)$. Since periodontitis is associated with an imbalance of oral microbiota $(15,16)$, these findings together suggest that chemerin might influence disease processes through controlling bacteria burden and/or composition in the oral cavity and by regulating immune cell infiltration.

The human oral cavity harbors diverse microbes that colonize gingiva and teeth $(15,17)$. The majority of bacteria in the oral cavity are organized in a biofilm structure. Primary (early) colonizers mostly belong to Streptococcus genera represented by $S$. oralis, $S$. mitis, and $S$. sanguinis, three of the most prevalent species of streptococci that are able to attach to enamel and epithelial surfaces (18). The streptococci coaggregate with other bacteria species represented by many genera, including Prevotella spp. and Actinomyces spp. Since many primary colonizers lack specific adhesins required for coaggregation, assembly of a more diverse and larger community is promoted by specific bacterial species such as Fusobacterium nucleatum. Usually found in the middle layer of a biofilm, F. nucleatum coordinates the coaggregation of early and late colonizers (16). Notably, colocalization of F. nucleatum with so-called "red complex" pathogens, such as Treponema denticola, Porphyromonas gingivalis, and Tannerella forsythia (19), suggests that integration of these pro-inflammatory and tissue-destructive pathogens to dental plaque is $F$. nucleatum dependent (20-22).

The oral cavity, in common with other portals of microbe entry, contains a variety of AMPs that can restrict the growth of bacteria and prevent potential pathologic outcomes. Salivary glands, epithelial cells, and oral cavity-recruited neutrophils produce over 45 AMPs that are detected in saliva and gingival crevicular fluid. These include cathelicidins (LL37), $\alpha$-defensins, $\beta$-defensins, histatins, and secretory leukocyte protease inhibitor (SLPI) (23-26). Because AMPs utilize different strategies to restrict microbial growth $(24,27)$, their diversity may be important for independently controlling the load, composition, and location of microbial communities in the oral cavity and for maintaining oral homeostasis.

Here, we report that chemerin directly acts on specific oral bacteria strains and exhibits chemotactic activity in gingivitis patient samples. Together, these findings suggest that antimicrobial and chemoattractant chemerin can shape the oral microbiome and coordinate oral immune defense mechanisms.

\section{MATERIALS AND METHODS}

\section{Materials}

Chemerin peptide 4 (VRLEFKLQQTSCRKRDWKKP) (p4) and scramble peptide 4 (DPWLKVRKFQTLKQREKRCS) (scp4) were chemically synthesized by ChinaPeptide (Shanghai, China). Chemically synthesized LL37 was from Emory Microchemical Facility (Atlanta, GA, USA). Recombinant human full-length chemerin variant chem163S and chemerin variant chem157S, lacking 6 aa at C-terminus were produced in Pichia pastoris. DNA fragments corresponding to the desired chemerin proteins were amplified by PCR and cloned into the pPIC9K expression vector (Life Technologies, Carlsbad, CA, USA) using the overlapextension PCR method (28). Both constructs lacked the 20 aa chemerin signal peptide but had the hexahistidine tag (His-tag) and the enterokinase cleavage site added to their $\mathrm{N}$ terminus. The identity of created constructs was verified by sequencing (Genomed, Poland). Recombinant chemerin isoforms were produced using P. pastoris strain GS115 ( His $^{-}$), transformed with the SalI-linearized pPIC9-chemerin construct. Recombinant proteins were purified from the supernatants of His + transformants using Ni-Sepharose 6 Fast Flow (GE Healthcare, Uppsala, Sweden). The recombinant chemerin variants were eluted with $500 \mathrm{mM}$ imidazole and dialyzed against phosphate buffered saline (PBS). The molecular weight and purity of the obtained proteins was determined by SDS-PAGE and Coomassie Blue staining. Since the final recombinant chemerin variants contained a His-tag, we also evaluated in parallel a His-tag free, HPLC-purified chemerin variant lacking 16 aa at the C-terminus, chem147S $(1,5)$, with similar results (data not shown). Recombinant human SLPI was produced as previously described (29).

\section{Human Samples Collection}

Unstimulated whole saliva samples were collected from healthy volunteers $[n=15$, male:female 5:10; age $28.5 \pm 4.8(21-36)]$. The participants rinsed their mouth with water before the collection. Saliva samples were collected $10 \mathrm{~min}$ later and centrifuged twice $(10,000 \times g, 5 \mathrm{~min})$ to remove cellular debris and stored at $-80^{\circ} \mathrm{C}$ until used. Six patients with gingivitis and 15 patients with periodontitis were recruited in a private dental practice. Demografic and clinical data of the patients are listed in Table 1. Subgingival plaque and tissue were sampled from the deepest site per quadrant (in case of the gingivitis patients from the mesio-buccal site of the

TABLE 1 | Demographic and clinical data.

\begin{tabular}{lcc}
\hline & Gingivitis $(\boldsymbol{n}=\mathbf{6})$ & $\begin{array}{c}\text { Periodontitis } \\
(\boldsymbol{n}=\mathbf{1 5})\end{array}$ \\
\hline $\begin{array}{l}\text { Age: mean (range) } \\
\text { Male/female }(n)\end{array}$ & $46.3(17-78)$ & $63.9(51-78)$ \\
$\begin{array}{l}\text { Sites with PD } \geq 5 \mathrm{~mm}(n ; \\
\text { mean } \pm \mathrm{SD})\end{array}$ & $1 / 5$ & $5 / 10$ \\
Sites with AL $\geq 5 \mathrm{~mm}(n ;$ & 0 & $10.7 \pm 6.5$ \\
mean \pm SD) & $0.67 \pm 1.03$ & $23.1 \pm 15.0$ \\
BOP (\%; mean \pm SD) & & \\
$\mathrm{Pl}(\% ;$ mean \pm SD) & $44 \pm 15$ & $39 \pm 14$ \\
\end{tabular}

$P D$, probing depth; $A L$, attachment loss; $B O P$, bleeding on probing; $P l$, plaque index. 
first molar) by inserting each an endodontic paper-point (ISO 055) for $30 \mathrm{~s}$ into the pocket until resistance felt. Paper-points were pooled, transferred into a tube and RNAlater ${ }^{\mathrm{TM}}$ storage solution (Sigma-Aldrich) was added. Not earlier than $24 \mathrm{~h}$ later, gingival crevicular wash-out (GCF) was obtained as previously described (30). Immediately after sampling, paper-points were stored at $-20^{\circ} \mathrm{C}$ and GCF samples at $-80^{\circ} \mathrm{C}$ until assayed. The total protein concentration in saliva and GCF was determined by bicinchoninic acid assay (Sigma-Aldrich). The patients study protocol was approved by the Ethical Commission of the University of Leipzig. All subjects gave written informed consent in accordance with the Declaration of Helsinki.

\section{PCR}

DNA and RNA was simultaneously extracted from the paper-points using innuPREP RNA/DNA mini kit (Analytic Jena AG) according to the manufacturer's instruction. DNA was used for real-time PCR analysis of the major periodontopathogens as previously described (31). RNA was converted to cDNA using the GoScript ${ }^{\mathrm{TM}}$ Reverse Transcription System (Promega) according to the manufacturers' instructions. qPCR was performed using GoTaq ${ }^{\circledR}$ qPCR Master Mix (Promega) and primers specific for P. gingivalis proteases (32): $r g p A, 5^{\prime}$-TATCCTTCGTGATGTGCGTG-3', $5^{\prime}$-GCTGTAACGGGAGAAGCAAT-3'; rgpB, $5^{\prime}$-CATTCTCCT CTCTGTTGGGA-3', 5' ${ }^{\prime}$-CGTAGGGGATTTGATCAGGA-3'; $k g p, 5^{\prime}$-TCAAGCAGTCGATGCAAGC-3', $5^{\prime}$-ACTTGGGTCAG TTCTTGTCC-3'; and sod, 5'-AATTCCACCACGGTAAGC AC-3' , 5' -TTCTCGATGGACAGTTTGCC-3'; as well as human chemerin 5'-TGGAAGAAACCCGAGTGCAAA-3', 5' -AGAAC TTGGGTCTCTATGGGG-3' , and GAPDH, 5'-GACAGTCAGC CGCATCTTCT-3', 5' -TTAAAAGCAGCCCTGGTGAC-3'. The relative gene expression normalized to sod $(\operatorname{rgpA}, \operatorname{rgpB}, \mathrm{kgp})$ and GAPDH (chemerin) was calculated using the $2^{-\triangle \Delta C T}$ method (10, $33,34)$.

\section{ELISA}

Chemerin levels in saliva and GCF samples were quantified by ELISA. Monoclonal mouse anti-human chemerin (R\&D System) and biotin-labeled polyclonal goat anti human chemerin (R\&D System) Abs were used to detect chemerin. HRP-labeled streptavidin (BD Pharmingen) was used to bind the biotinylated Abs. The plate was developed with 3,3',5,5'-Tetramethylbenzidine substrate (TMB) (BD Biosciences), stopped using 0.18M sulfuric acid and measured at $450 \mathrm{~nm}$. Alternatively, commercially available chemerin ELISA kit (R\&D Systems) was used according to the manufacturer's recommendations.

\section{Bacterial Strains and Culture Conditions}

The bacterial strains used in this study were standard strains except Sov-A mutant with replacement of sov gene (PG0809/10) in Porphyromonas gingivalis W83 with a tetQ cassette (Tc $1 \mu \mathrm{g} / \mathrm{ml}$, Sigma-Aldrich). P. gingivalis ATCC 33277 was cultured in Brain Heart Infusion broth (BHI) (Becton Dickinson) supplemented with yeast extract (5 g/l, Lab Empire), hemin (10 mg/l, SigmaAldrich), L-cysteine (0.25 g/l, Lab Empire), menadione ( $0.5 \mathrm{mg} / \mathrm{l}$, Sigma-Aldrich), and defibrinated sheep blood (5\% v/v). P. gingivalis W83 and P. gingivalis Sov-A were cultured in Scheadler broth
(BTL) supplemented with menadione $(0.5 \mathrm{mg} / \mathrm{l})$, defibrinated sheep blood (5\% v/v). Prevotella intermedia 17, Fusobacterium nucleatum ATCC 10953, F. nucleatum ATCC 25586 were cultured in Trypticase soy broth (TSB) (Sigma-Aldrich) supplemented with defibrinated sheep blood $(5 \% \mathrm{v} / \mathrm{v})$. Tannerella forsythia ATCC 43037 was cultured in TSB supplemented with hemin ( $5 \mathrm{mg} / \mathrm{l}), \mathrm{N}$-acetyl muramic acid (10 mg/l, Sigma-Aldrich) and defibrinated sheep blood (5\% v/v). Streptococcus salivarius ATCC 7073, S. sanguinis ATCC 10556, S. oralis ATCC 35037, S. gordonii ATCC 10558 were cultured in BHI. P. gingivalis, P. intermedia, F. nucleatum, and $T$. forsythia were grown in an anaerobic atmosphere using a GasPak ${ }^{\mathrm{TM}}$ EZ Anaerobe Pouch System (BD). Streptococci were grown in a $5 \% \mathrm{CO}_{2}$ atmosphere using a GasPak $^{\mathrm{TM}} \mathrm{EZ} \mathrm{CO} \mathrm{CO}_{2}$ Pouch System (BD).

\section{Microdilution Assay (MDA)}

Overnight cultures of bacterial strains were sub-cultured to fresh media and grown to mid-logarithmic phase. Bacteria were harvested, washed three times with Dulbecco's PBS and diluted to $4 \times 10^{5} \mathrm{CFU} / \mathrm{ml}$ with PBS. Bacteria were then incubated for $3 \mathrm{~h}$ with either $\mathrm{p} 4$ at $100 \mu \mathrm{M}$ or scp4 (negative control) at $100 \mu \mathrm{M}$. LL37 $(50 \mu \mathrm{g} / \mathrm{ml})$ was used as a positive control.

\section{Minimal Inhibitory Concentration (MIC) Determination}

Minimal inhibitory concentration was determined as previously described (35) with some modifications. Briefly, bacteria were prepared as described above and diluted to $4 \times 10^{6} \mathrm{CFU} / \mathrm{ml}$ with $0.2 \%$ bovine serum albumin in PBS. Series of twofold dilution of peptide $\mathrm{p} 4$ were prepared in PBS to provide final concentration range $400-0.4 \mu \mathrm{g} / \mathrm{ml}(154-0.15 \mu \mathrm{M})$. Bacterial suspensions were mixed with p4 or PBS (control) and incubated at $37^{\circ} \mathrm{C}$ overnight. The MIC was defined as the lowest antimicrobial concentration which prevented visible growth of bacteria.

\section{Biofilm Formation}

Overnight bacterial cultures were harvested, washed with PBS and adjusted to $\mathrm{OD}_{600 \mathrm{~nm}}=1$. One hundred microliters of bacterial suspension previously diluted 1:100 in BTL supplemented with menadione $(0.5 \mathrm{mg} / \mathrm{l})$ were grown in flat-bottomed 96 -well polystyrene microplates (Sarstedt) under anaerobic condition. After incubation for $48 \mathrm{~h}$, supernatant containing planktonic cells and media was gently removed and replaced with p4 $(100 \mu \mathrm{M})$ in PBS or PBS alone (control). The viability of the bacterial cells in biofilm after $5 \mathrm{~h}$ treatment with $\mathrm{p} 4$ was determined using The BacTiter-Glo ${ }^{\mathrm{TM}}$ Microbial Cell Viability Assay (Promega) based on ATP-based luminescence quantification. The number of viable bacteria was conducted by counting $\mathrm{CFU} / \mathrm{ml}$. Following the incubation with $\mathrm{p} 4$, biofilms were resuspended, serially diluted and plated on an agar medium.

\section{Protease Activity Assay}

Overnight cultures of $P$. gingivalis W83 strain were adjusted to $\mathrm{OD}_{600 \mathrm{~nm}}=1$ with BTL and centrifuged for $15 \mathrm{~min}$ at $6,000 \times g$. The conditioned media were harvested and stored at $4^{\circ} \mathrm{C}$ until used. Conditioned media and GCF samples were tested for protease 
activity using $\mathrm{N}_{\alpha}$-Benzoyl-L-Ala 4-nitroanilide hydrochloride and $\mathrm{N}$-(p-Tosyl)-Gly-Pro-Lys 4-nitroanilide acetate salt (both from Sigma) hydrolyzed by Rgp and Kgp gingipains, respectively. Ten microliters of bacterial conditioned media (corresponding to $10^{7} \mathrm{CFU}$ ) or $4 \mu \mathrm{l} \mathrm{GCF} \mathrm{samples} \mathrm{(each} \mathrm{containing} 48 \mu \mathrm{g}$ of total protein) were diluted with TNC buffer $(200 \mathrm{mM}$ Tris, $150 \mathrm{mM}$ $\mathrm{NaCl} 5 \mathrm{mM} \mathrm{CaCl}_{2} \mathrm{pH}=7.6$ ) with $10 \mathrm{mM} \mathrm{L}$-cysteine to a final volume of $100 \mu \mathrm{l}$ (for bacterial supernatants) or $50 \mu \mathrm{l}$ (for GCF). To inhibit gingipains, $1 \mu \mathrm{M}$ of either KYT-1 (RgpA and RgpBspecific inhibitor) or KYT-36 (Kgp-specific inhibitor) (36), were added. The mixtures were then preincubated for $20 \mathrm{~min}$ at $37^{\circ} \mathrm{C}$. Equal volume of Rgp or Kgp substrate diluted in TNC buffer was then added to final substrate concentration of $1 \mathrm{mM}$ and final volume of either 100 or $200 \mu$ l. The increase of absorbance at $\lambda=405 \mathrm{~nm}$ as a measure of hydrolyzed substrate was recorded for at least $90 \mathrm{~min}$ at $37^{\circ} \mathrm{C}$, using a microplate reader (Tecan Infinite M200).

\section{Chemotaxis Assay}

GCF samples from gingivitis and periodontitis patients were tested in an in vitro chemotaxis assay using $5 \mu \mathrm{m}$ pore Transwell inserts (Costar) and murine pre-B lymphoma cell line L1.2 or L.1.2 cells stably transfected with human recombinant CMKLR1 (CMKLR1/L1.2). Chemotaxis assay was performed using chemotaxis media [RPMI $1640 \mathrm{w} / \mathrm{L}$-glutamine supplemented with $25 \mathrm{mM}$ HEPES (Biowest) and 10\% FBS (Gibco)]. One hundred microliters of cells $\left(2 \times 10^{5}\right.$ cells/well $)$ were added to the top well and tested samples, each containing $1 \mathrm{nM}$ of chemerin (as determined by ELISA) were added to the bottom well in a $600 \mu \mathrm{l}$ volume. Migration was assayed for $2 \mathrm{~h}$ at $37^{\circ} \mathrm{C}$. The inserts were then removed and cells that had migrated through the filter to the lower chamber were collected and counted by flow cytometry (LSRII, BD). The results are presented as\% input migration.

\section{Chemerin Processing by Gingipains}

Ten microliters of conditioned media derived from overnight cultures of $P$. gingivalis W83 (corresponding to $10^{7} \mathrm{CFU}$ ) were mixed with $5 \mu$ lof TNC buffer with $10 \mathrm{mM} \mathrm{L-cysteine.} \mathrm{For} \mathrm{inhibi-}$ tion test, KYT-1 and KYT-36 were added to a final concentration of $1 \mu \mathrm{M}$. The samples were preincubated for $20 \mathrm{~min}$ at $37^{\circ} \mathrm{C}$, followed by overnight incubation with $50 \mathrm{ng}$ human recombinant chemS157. The samples were then analyzed in an in vitro chemotaxis assay.

\section{RESULTS}

To determine whether chemerin serves as AMP against oral bacteria, we first analyzed chemerin protein levels in saliva of healthy individuals with no signs of periodontal disease. In agreement with a recent report (13), chemerin was found in saliva from healthy donors, in the concentration of $1.3 \pm 0.5 \mathrm{ng} /$ mg total protein (mean $\pm \mathrm{SD}, n=15$ ). Next, we determined chemerin RNA and protein levels in gingiva samples from patients suffering from periodontal inflammation. We analyzed samples from patients with either gingivitis (gum inflammation) or periodontitis, a more severe form of gum disease associated with progressive alveolar bone loss around the teeth. Donor demographics and clinical parameters are included in Table 1.

As anticipated, periodontitis patients presented with significantly elevated colony counts of the periodontopathogen $P$. gingivalis and its associated gingipain proteases (RgpA, RgpB, and Kgp) compared to patients with gingivitis (Table 2). Chemerin

TABLE 2 | Microbiological and chemerin expression data in gingival samples from patients with peridontal disease.

\begin{tabular}{|c|c|c|c|c|c|}
\hline & \multicolumn{2}{|c|}{ Gingivitis $n=6$} & \multicolumn{3}{|c|}{ Periodontitis $n=15$} \\
\hline & $\begin{array}{l}\text { Positive samples with } \\
\text { bacteria loads } \geq 10^{5} \\
\text { ( } n / \text { total) }\end{array}$ & $\begin{array}{l}\text { Median [interquartile } \\
\text { range] } \times 10^{5}\end{array}$ & $\begin{array}{l}\text { Positive samples with } \\
\text { bacteria loads } \geq 10^{5} \\
\text { ( } n / \text { total) }\end{array}$ & $\begin{array}{l}\text { Median [interquartile } \\
\text { range] } \times 10^{5}\end{array}$ & $\begin{array}{l}p \text { (Mann- } \\
\text { Whitney) }\end{array}$ \\
\hline A. actinomycetemcomitans & $1 / 6$ & $0.00[0.00 ; 3.44]$ & $7 / 15$ & $0.00[0.00 ; 2.97]$ & 0.340 \\
\hline P. gingivalis & $5 / 6$ & 0.07 [0.01; 3.84] & $13 / 15$ & $1.03[0.51 ; 2.10]$ & $0.029^{\star}$ \\
\hline T. forsythia & $4 / 6$ & $1.13[0.00 ; 16.9]$ & $15 / 15$ & 1.66 [0.39; 33.3] & 0.080 \\
\hline \multirow[t]{2}{*}{ T. denticola } & $3 / 6$ & $0.22[0.00 ; 1.32]$ & $6 / 15$ & $0.00[0.00 ; 0.11]$ & 0.340 \\
\hline & $\begin{array}{l}\text { Positive samples } \\
\text { (n/total) }\end{array}$ & $\begin{array}{l}\text { Median [interquartile } \\
\text { range] } \times 10^{5}\end{array}$ & $\begin{array}{l}\text { Positive samples } \\
\text { (n/total) }\end{array}$ & $\begin{array}{l}\text { Median [interquartile } \\
\text { range] } \times 10^{5}\end{array}$ & \\
\hline rgpA RNA relative to sod & $1 / 6$ & 0.00 [0.00; 0.45] & $12 / 15$ & 0.35 [0.02; 2.57] & $0.023^{*}$ \\
\hline $\operatorname{rgp} B$ RNA relative to sod & $1 / 6$ & $0.00[0.00 ; 3.16]$ & $12 / 15$ & $0.76[0.22 ; 3.38]$ & $0.045^{\star}$ \\
\hline kgp RNA relative to sod & $1 / 6$ & $0.00[0.00 ; 2.77]$ & $12 / 15$ & $0.52[0.26 ; 158.3]$ & $0.023^{\star}$ \\
\hline \multirow{2}{*}{$\begin{array}{l}\text { Chemerin mRNA relative to } \\
\text { GAPDH }\end{array}$} & $5 / 6$ & $0.33[0.00 ; 1.63]$ & $13 / 15$ & $1.04[0.31 ; 1.93]$ & 0.205 \\
\hline & $\begin{array}{l}\text { Positive samples } \\
\text { (n/total) }\end{array}$ & $\begin{array}{l}\text { Median [interquartile } \\
\text { range] }\end{array}$ & $\begin{array}{c}\text { Positive samples } \\
\text { (n/total) }\end{array}$ & Median [interquartile range] & \\
\hline $\begin{array}{l}\text { Chemerin protein ( } \mathrm{ng} / \mathrm{mg} \\
\text { total protein) }\end{array}$ & $6 / 6$ & $4.37[0.43 ; 17.84]$ & $15 / 15$ & $6[2.81 ; 10.30]$ & 0.340 \\
\hline
\end{tabular}

*Statistically significant. 
TABLE 3 | Correlation of chemerin gene expression and chemerin protein levels with clinical and microbiological variables $(\boldsymbol{P}$ and $\boldsymbol{R}$ are only given if $p$ was statistically significant) Spearman Rho.

\begin{tabular}{lcc}
\hline & \multicolumn{2}{c}{ Chemerin expression } \\
\cline { 2 - 3 } & $\boldsymbol{R}$ & $\boldsymbol{P}$ \\
\hline $\mathrm{PD} \geq 5 \mathrm{~mm}(n)$ & 0.472 & 0.031 \\
$\mathrm{AL} \geq 5 \mathrm{~mm}(n)$ & 0.451 & 0.034 \\
$\mathrm{BOP}(\%)$ & & n.s. \\
$\mathrm{Pl}(\%)$ & & n.s. \\
A. actinomycetemcomitans & & n.s. \\
$P$. gingivalis & 0.462 & 0.035 \\
T. forsythia & 0.550 & 0.010 \\
T. denticola & & n.s. \\
Chemerin protein level & & n.s. \\
\hline
\end{tabular}

$P D$, probing depth; $A L$, attachment loss; BOP, bleeding on probing; Pl, plaque index; n.s., not significant.

gene expression tended to be higher in periodontal region samples from the periodontitis group compared to gingivitis, although the difference was not statistically significant (Table 2). Likewise, GCF samples from gingivitis and periodontitis patients contained on average similar levels of chemerin $(5.6 \pm 1.3 \mathrm{ng} / \mathrm{mg}$ of total protein vs. $6.3 \pm 1.1 \mathrm{ng} / \mathrm{mg}$, mean \pm SEM) and Table 2 . While there were no significant correlations between chemerin protein levels and the examined clinical/microbiological variables (data not shown), there was a significant positive correlation between chemerin gene expression and clinical probing depth and attachment loss measurements as well as abundance of $P$. gingivalis and T. forsythia in the pocket samples (Table 3). Together these data suggest that chemerin may be involved in the regulation of microbiota in the oral cavity under both homeostatic and inflammatory conditions.

We next explored whether chemerin exhibits antimicrobial activity against selected oral bacterial species that are differently located in oral biofilm and differ in pathogenic potency. Since chemerin peptide 4 (p4), corresponding to the internal Val ${ }^{66}-\mathrm{Pro}^{85}$ region of human chemerin, is primarily responsible for chemerin antimicrobial effects (9), we tested selected components of the oral microbiota for sensitivity to $\mathrm{p} 4$ by MDA assay. This assay detects the planktonic (free floating) form of bacteria. Scramble peptide $4(\operatorname{scp} 4,100 \mu \mathrm{M})$ and oral antimicrobial agent LL37 $(11 \mu \mathrm{M})$ (24), were used as a negative and positive controls, respectively. Chemerin peptide p4 $(100 \mu \mathrm{M})$ completely inhibited the growth of two out of four tested Streptococcus species, S. salivarius ATCC 7073 and S. sanguinis ATCC 10556, but not S. gordonii ATCC 10558 or S. oralis ATCC 35037. In contrast, LL37 completely inhibited the growth of S. gordonii ATCC 10558 but not S. oralis ATCC 35037 (Figure 1). Peptide p4 also completely inhibited the growth of two different strains of F. nucleatum; F. nucleatum ATCC 10953 and ATCC 25586. However, the growth of P. intermedia 17 or the red complex constituent T. forsythia (T. forsythia ATCC 43037) was not inhibited by p4, although they were largely susceptible to LL37-dependent growth inhibition (Figure 1). Likewise, only slight but significant inhibition of another red complex component $P$. gingivalis was noted, leading to survival of $78 \pm 9 \%$ of bacteria compared to the vehicle-treated $P$. gingivalis
ATCC 33277 (set as 100\%) or to the scramble p4 peptide control $(118 \pm 17 \%)$. The growth/viability of two other $P$. gingivalis strains (W83 and SOV) was not suppressed by p4, although LL37 significantly inhibited their growth (Figure 1). In contrast to p4, scp4 did not limit the growth of the tested strains, and in some cases even increased the number of viable counts of bacteria (Figure 1). The differential anti-microbial activity of p4 against oral bacteria was further demonstrated by MIC values, which were $50 \mu \mathrm{g} / \mathrm{ml}(19.2 \mu \mathrm{M})$ for the most sensitive Streptococci and F. nucleatum strains, and $400 \mu \mathrm{g} / \mathrm{ml}$ or more for less sensitive and resistant strains (Figure 2). We conclude that chemerin peptide 4 has the ability to limit the growth of specific oral cavity-resident bacteria, but exhibits variation in its ability to kill different species of oral microbes.

Next, we tested whether chemerin isoforms, either full-length, chemotactively inert chemS163, or the truncated, chemotactively active chemS157 (both containing the internal p4 sequence) affect the growth of $\mathrm{p} 4$-sensitive $F$. nucleatum and largely resistant $P$. gingivalis. Both chemS163 and chemS157 significantly suppressed the growth of F. nucleatum ATCC 25586 at $2 \mu \mathrm{M}$ $(67 \pm 23$ and $62 \pm 26 \%$ viability, mean $\pm S D$, compared with control); however, their inhibitory effects were less robust than $2 \mu \mathrm{M}$ p4 (16 $\pm 3 \%)$ (Figure 3). On the other hand, neither chemerin isoforms showed significant antimicrobial activity against $P$. gingivalis ATCC 33277 (Figure 3). These data suggest that not only chemerin-derived peptide 4 but also full-length chemerin and its endogenous bioactive isoform inhibit the growth of selected oral bacteria.

To evaluate potential additive or synergistic effects between chemerin and other oral AMPs, we next tested the antimicrobial activity of combinations of p4 with LL37 and SLPI. AMPs were tested at suboptimal concentrations that resulted in $>30$ and $<90 \%$ growth inhibition when applied alone, based on previously determined MIC values for each AMP (Figure 2 and data not shown). Chemerin peptide $\mathrm{p} 4(2.5 \mu \mathrm{g} / \mathrm{ml})$ given in combination with LL37 $(2.5 \mu \mathrm{g} / \mathrm{ml})$ and/or SLPI $(10 \mu \mathrm{g} / \mathrm{ml})$, in each case was significantly more bactericidal against $S$. salivarius and F. nucleatum than each agent given alone (Figure 4). These data suggest that all three AMPs cooperate for optimal restriction of bacterial growth in oral cavity.

The majority of bacteria in the oral cavity grow attached to the teeth and epithelial surfaces as biofilm components. Therefore, we next determined whether $\mathrm{p} 4$ inhibits the attached forms of $F$. nucleatum and $P$. gingivalis, in addition to suppressing the planktonic form of the bacteria (Figure 1). F. nucleatum and $P$. gingivalis were cultured for $48 \mathrm{~h}$ under biofilm-like conditions and then treated with $\mathrm{p} 4$ or vehicle PBS for $5 \mathrm{~h}$. The growth of the attached form of F. nucleatum was markedly suppressed by $\mathrm{p} 4$ (Figure 5). In contrast, $P$. gingivalis was resistant to $\mathrm{p} 4$ treatment (Figure 5). These data suggest that chemerin exerts antimicrobial activity during either biofilm or planktonic life cycles of $F$. nucleatum but is minimally or not effective against planktonic and biofilm form, respectively, of $P$. gingivalis.

Since chemerin is chemoattractant for immune cells that are implicated in the pathogenesis of periodontal disease, including DCs, macrophages, and NK cells (37-41), we next tested whether chemerin in GCF samples from individuals with gingivitis and 


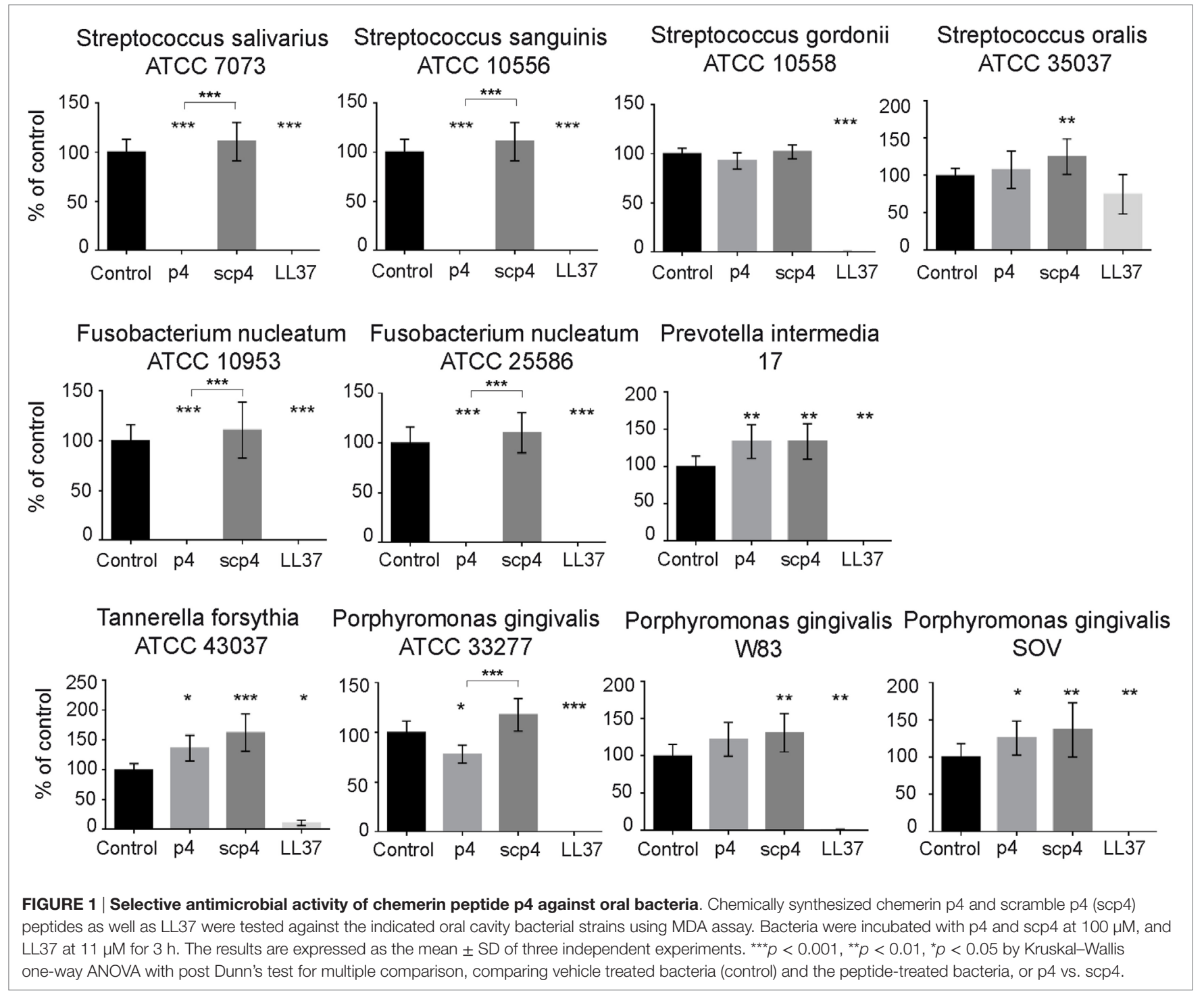

periodontitis is able to support chemotaxis of chemerin responsive CMKLR1 ${ }^{+}$cells. We performed in vitro transwell chemotaxis assays using the GCF samples each containing $1 \mathrm{nM}$ endogenous chemerin (as determined by ELISA) and $1 \mathrm{nM}$ bioactive chemS157 as a positive control. CMKLR1-transfected L1.2 cells migrated to GCF from gingivitis patients $(4.2 \%)$ but showed little migration to GCF from periodontitis individuals (0.5\%) (Figure 6A). When CMKLR1-negative parental L1.2 cell were used instead of CMKLR1/L1.2 transfectants, very little chemotaxis was detected (Figure 6A). These data indicate that the observed response was chemerin-dependent.

Since GCF samples from the gingivitis and periodontitis groups contained similar levels of chemerin (Table 2) but markedly differed in the attractant activity (Figure 6A), these data suggest that chemerin is inactivated in periodontitis patients, possibly by factors secreted by periodontal pathogens. The possible candidates include $P$. gingivalis-produced gingipains (RgpA, RgpB, and Kgp) (Table 2). To determine whether these proteases inactivate chemerin, $P$. gingivalis conditioned media were incubated with recombinant chemS157. The involvement of gingipains in chemerin inactivation was examined using conditioned media in which these enzymes were blocked by gingipain-specific inhibitors prior to incubation with chemS157. As shown in Figure 6B, CMKLR1-transfected L1.2 cells migrated robustly in response to chemS157, but almost no migration was noted when chemS157 was treated with $P$. gingivalis conditioned media. The effect of the conditioned media was largely reversed by gingipain-specific inhibitors, indicating that gingipains inactivate the chemoattactant activity of chemerin.

\section{DISCUSSION}

Chemerin is expressed by many different epithelial tissues and plays a role in skin immune defense $(1,9,10)$. Here, we demonstrate that chemerin is also expressed in the oral cavity, where it 

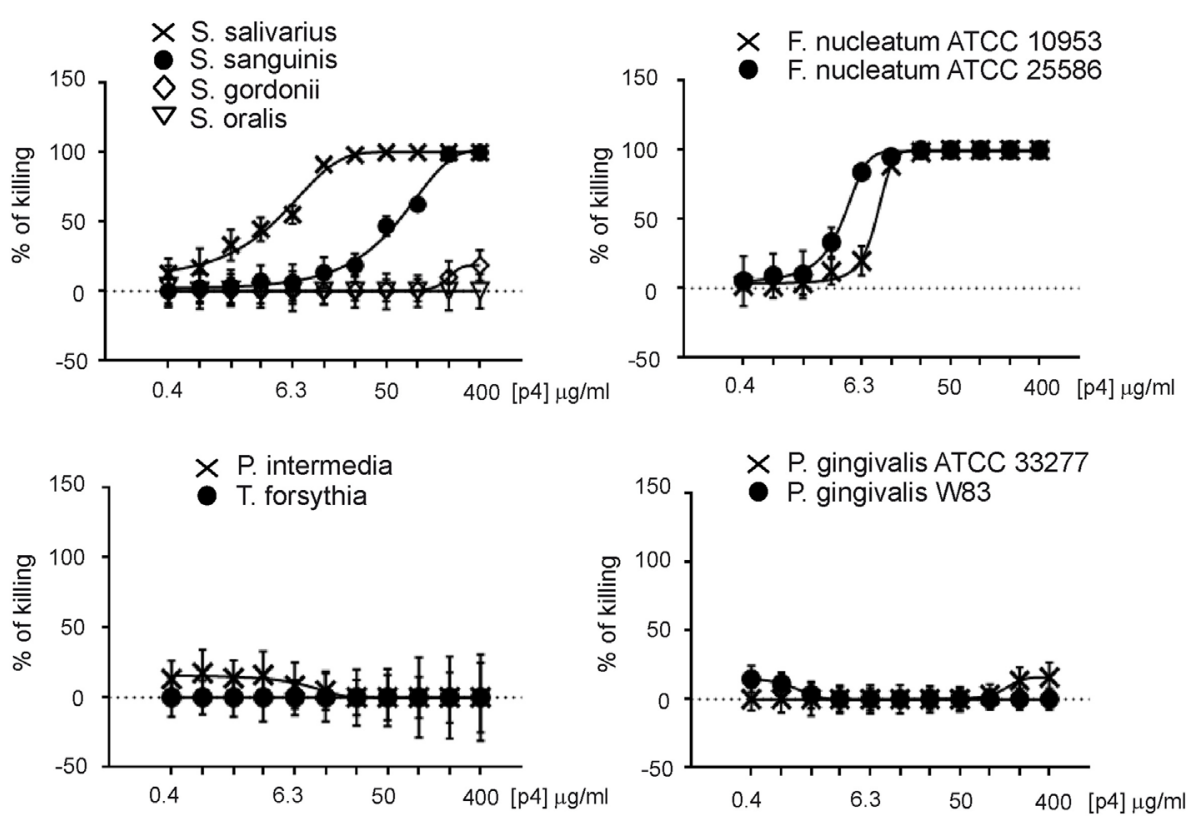

FIGURE 2 | Minimal inhibitory concentration (MIC) values for indicated oral cavity microorganisms. Data indicate\% of killing for the indicated strain. The MIC was defined as the lowest concentration of p4 showing no visible growth (100\% of killing). Mean \pm SD of three independent measurements is shown.

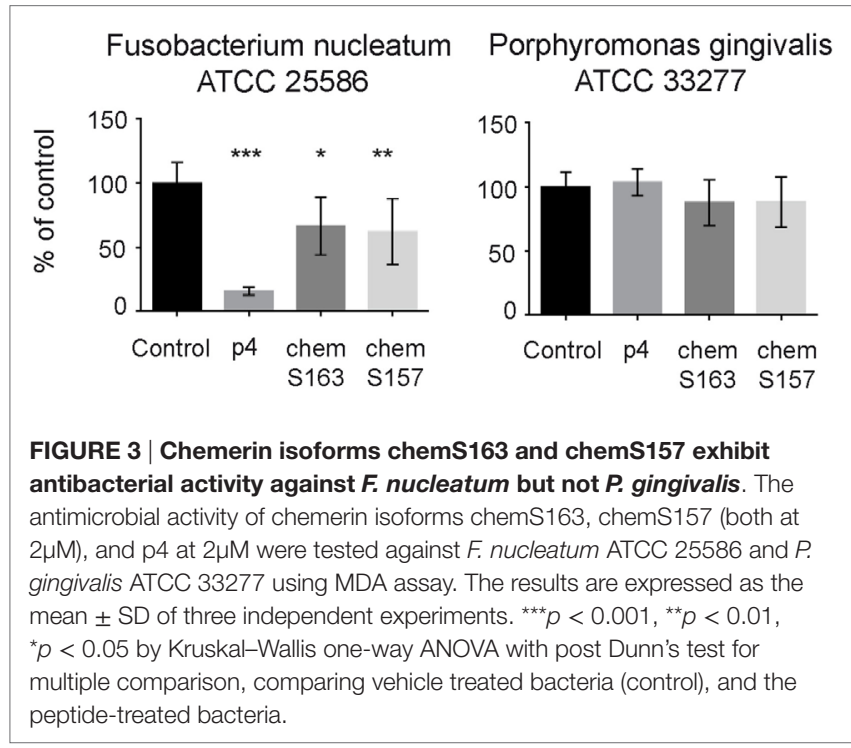

likely contributes to antibacterial defense as an antibacterial agent and as a chemoattractant for immune cells. Using human samples, we showed that chemerin mRNA and protein is present in tissue cavity samples of individuals with inflammatory gum disease, and that chemerin protein is present in the saliva of healthy donors. Both planktonic and attached cultures of bacteria that specifically inhabit the oral cavity were sensitive to chemerin-derived peptide-p4 and chemerin protein isoforms. Thus, the physiological role of chemerin in the oral cavity might be to directly mold the microbiome. Furthermore, chemerin present in GCF from gingivitis patients retained leukocyte chemoattractant activity rendering it uniquely suited to position DCs, macrophages, and/ or NK cells to sites of gum inflammation, where they may provide immune protection.

Our findings add chemerin to the list of potential endogenous oral AMPs. However, in contrast to other antimicrobial agents, such as LL37, chemerin exhibited a rather narrow spectrum of activity against oral microbiota (Figures 1 and 2). Among inhabitants of the periodontal biofilm, only Streptococcus species and most notably F. nucleatum strains were identified as p4 targets. Several P. gingivalis strains, including SOV were not inhibited by $\mathrm{p} 4$. Given that the $P$. gingivalis SOV strain is defective in secretion of gingipains (42), these data suggest that that resistance of $P$. gingivalis to $\mathrm{p} 4$ is not due to degradation of $\mathrm{p} 4$ by these enzymes. This differential ability of either $\mathrm{p} 4$ or chemerin to inhibit the growth of oral bacterial strains suggests that chemerin is not a direct chemical shield against pathogens but rather serves to shape the oral microbial ecology. By acting on a defined spectrum of microbes, chemerin might limit an assembly of a disease-provoking microbiota. For example, the presence of chemerin-sensitive F. nucleatum benefits the entire community of bacterial inhabitants in subgingival plaque due to its unique ability to cooperate with other bacterial species in biofilm formation (16). Recent reports associate periodontal pathogenicity with an imbalance in microbiota, known as dysbiosis $(15,43$, 44). Therefore, through curtailing expansion of F. nucleatum, chemerin may help to maintain balance in the resident microbial community.

In common with other AMPs, chemerin in saliva or the GCF samples was found in less-than-effective concentrations to exert bactericidal effect on its own [Table 2; Figure 2; (13, 14, 24)]. 


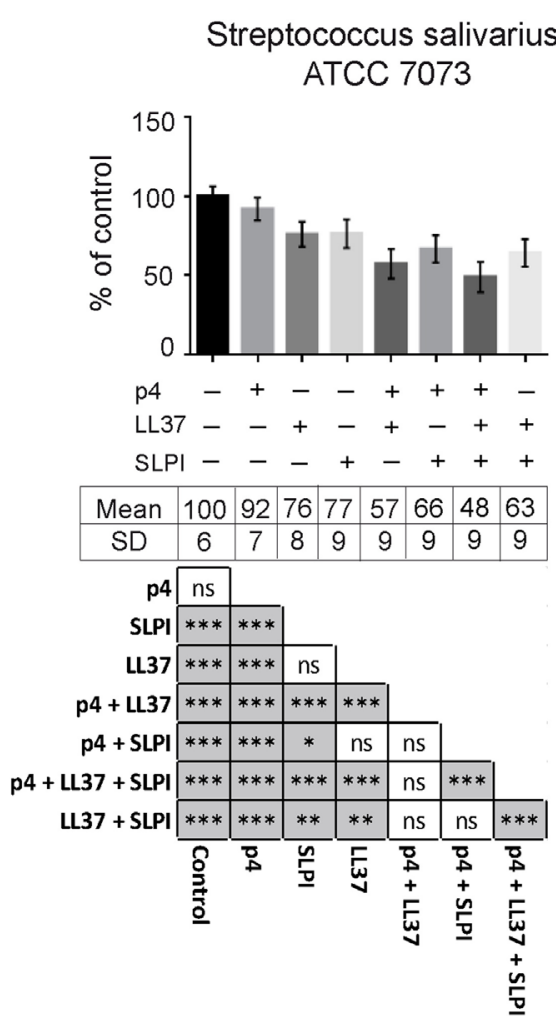

Fusobacterium nucleatum ATCC 25586

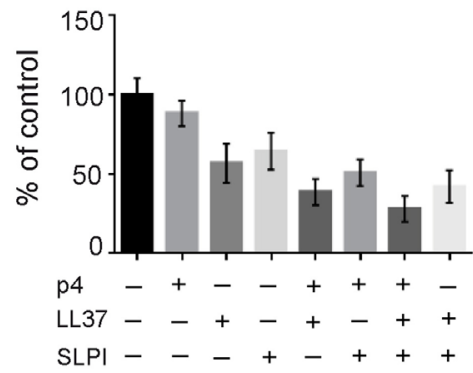

$\mathrm{SLPI}--++-++$

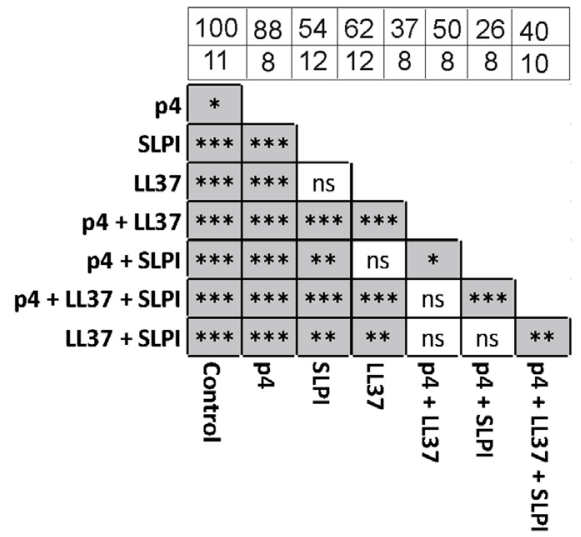

FIGURE 4 | Peptide p4 cooperates with LL37 and secretory leukocyte protease inhibitor (SLPI) in limiting growth of specific oral bacteria. Chemically synthesized peptides, p4 and LL37 as well as recombinant human SLPI were tested against indicated oral cavity bacterial strains using MDA assay. Bacteria were incubated with $2.5 \mu \mathrm{g} / \mathrm{ml} \mathrm{p} 4$ and LL37, and $10 \mu \mathrm{g} / \mathrm{ml}$ SLPI for $3 \mathrm{~h}$. The results are expressed as the mean \pm SD of three independent experiments. ${ }^{*} p<0.05$, ${ }^{* *} p<0.01,{ }^{* \star *} p<0.001$, ns, not significant by Kruskal-Wallis one-way ANOVA with post Dunn's test for multiple comparison.
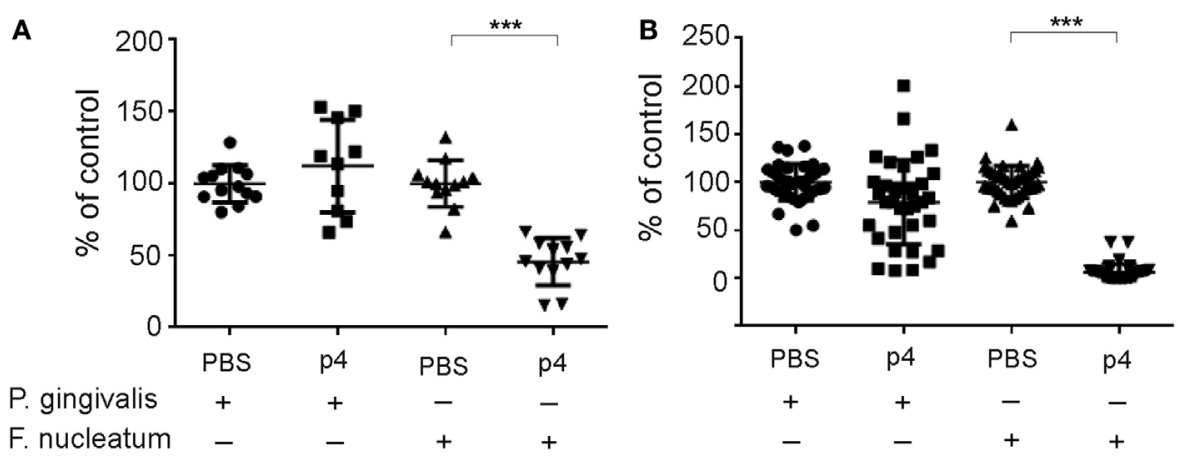

FIGURE 5 | Peptide p4 suppresses growth of $\boldsymbol{F}$. nucleatum in biofilm in vitro. F. nucleatum ATCC 25586 and $P$. gingivalis W83 were grown attached in polystyrene microplates for $48 \mathrm{~h}$ followed by the incubation with $100 \mu \mathrm{M}$ p4 or vehicle (PBS) for $5 \mathrm{~h}$. The viability of bacteria was then determined by ATP-based luminescence quantification (A) or CFU counting (B). The results are shown as $\%$ of control (vehicle treated bacteria) and are expressed as the mean \pm SD of five independent experiments. ${ }^{\star \star \star} p<0.001$, by $t$ test, comparing vehicle vs. p4 for each bacteria.

Since chemerin levels at oral infection sites are likely to be higher than in CGF wash outs, local chemerin may be present in sufficient quantities to control oral microbiota by itself. However, chemerin may be more effective as an oral AMP by acting in concert with other antimicrobial agents. This is in-line with our findings showing additive inhibitory effects of p4, LL37, and SLPI on the growth of oral bacteria.

Certain AMPs serve a second role in host defense as leukocyte attractants, and chemerin has the capacity to play a similar dual role in the oral cavity. Chemerin-mediated chemotaxis, 
A

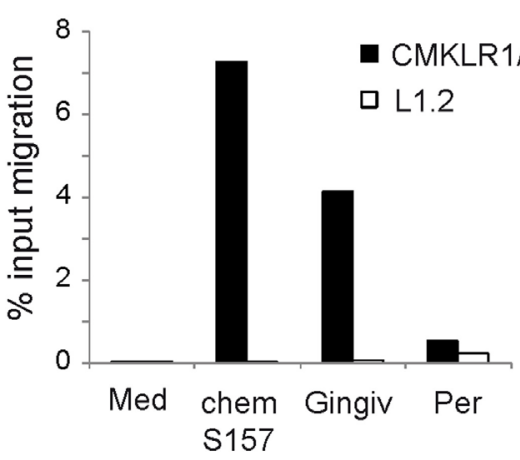

B

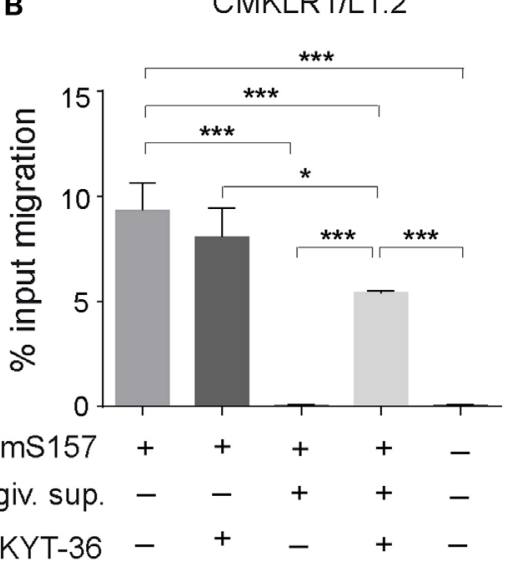

FIGURE 6 | GCF samples from gingivitis and periodontitis patients differ in chemerin-mediated chemotactic activity, and bioactive chemS157 is inactivated in gingipain-specific manner. (A) Chemotactic bioactivity of endogenous chemerin from gingivitis (Gingiv) and periodontitis (Per) samples, each containing $1 \mathrm{nM}$ endogenous chemerin as determined by ELISA was evaluated by in vitro CMKLR1/L1.2 cell or L1.2 parental cell migration. Data are from one experiment, showing two combined samples in each patient group, and are representative of two experiments and five patients in each group. Migration to bioactive recombinant chemS157 at 1nM, and chemotaxis medium (Med) is shown as a positive and negative control, respectively. (B) $1 \mathrm{nM}$ recombinant chemS157 was incubated with the conditioned media from $P$. gingivalis W83 (P. gingiv. sup). Where indicated the media were first treated with gingipain-specific inhibitors (KYT-1 + KYT-36), followed by incubation with chemS157. The samples were tested in chemotaxis using CMKLR1/L1.2 transfectants. The mean \pm SD from three experiments is shown. ${ }^{\star \star *} p<0.001,{ }^{\star} p<0.05$ by one-way ANOVA with post hoc Tukey Unequal N HSD test.

exhibited by the gingivitis samples (Figure 6A), may serve to enhance the recruitment of CMKLR1 ${ }^{+}$cells to inflamed gums. CMKLR1+ DCs, macrophages, and NK cells have been associated with inflammatory gum disease and reported to infiltrate the inflamed gingiva (37-41). Although their role in gingivitis or periodontitis is not well defined, they are considered to be a part of the defense mechanism against microbial challenge in dental biofilm (37-41). However, since the innate immune response to microbes can lead to excessive inflammation and its associated damaging effects on healthy host tissue, these cells may also contribute to the pathogenesis of periodontal disease (37-41). In contrast to gingivitis, periodontitis is associated with a marked reduction in chemerin bioactivity (Figure 6A). These data suggest that the chemoattractant is locally functionally compromised in patients with periodontitis. Several lines of evidence support the role for gingipains in chemerin inactivation: (1) mRNA encoding all three gingipains (RgpA, RgpB, and Kgp) was present in higher levels and in a larger number of patients with periodontitis compared with individuals with gingivitis (Table 2); and (2) P. gingivalis supernatants inactivated chemS157 in the gingipain-dependent manner (Figure 6B). However, in contrast to $P$. gingivalis conditioned media, we were not able to detect gingipain-specific enzymatic activity in GCF samples from either gingivitis or periodontitis individuals, which may be related to the substantial dilution (100-200x) of the wash samples (data not shown). Nevertheless, these data suggest that chemS157 is a novel gingipain substrate and that periodontal pathogens may utilize gingipains to subvert chemerin-dependent antimicrobial defense mechanisms.

Previous studies reported significantly higher levels of chemerin in saliva from periodontitis patients compared with gingivitis patients and healthy controls (13), and in GCF samples from periodontitis patients compared with healthy controls (14). Although in our studies we did not directly compare chemerin levels in saliva or GCF samples within the same groups of patients, chemerin levels were similar in GCF samples from periodontitis and gingivitis patients, with a trend for highler levels in the periodontitis group (Table 2). Chemerin is subject to posttranslational regulation by proteolytic processing, and chemerin protein levels might be altered by degrading proteolytic enzymes present in inflamed tissues. Likewise, local degradation of chemerin by proteases such as gingipains in samples from periodontitis patients might also explain why, despite a positive correlation between chemerin gene expression in the pocket samples and the clinical and microbial variables, chemerin protein levels were not similarly correlated (Table 3 ).

Increased levels of bioactive chemerin are present in gingivitis patient samples as opposed to periodontitis and thus are associated with less-severe gum disease. This broadly supports a protective role for chemerin signaling in the oral cavity. One of the possible mechanisms underlying bioactive chemerinmediated protection might involve production of antimicrobial agents by the infiltrating cells. Macrophages as well as NK cells are well-known to produce a variety of bactericidal compounds, including AMPs (45), and these agents might play an important role in containing infection. On the other hand, chemerin inactivation might help to limit excessive inflammation and tissue destruction, including bone loss observed during periodontitis. This is supported by findings that chemerin is a negative regulator of bone formation. Chemerin or CMKLR1 knock down in bone marrow-derived osteoblast precursor cells is associated with osteoblastogenesis (46). Since an imbalance between 
bone-forming osteoblast and bone-resorbing osteoclast is the underlying cause of bone loss in periodontitis (47), disruption of chemerin-mediated signaling may promote osteoblast development.

In summary, chemerin has the ability to directly and selectively destroy oral microbes and may therefore influence the incidence or progression of gum disease via altering the composition of the oral microbiome. In addition, through guiding immune cells to infection sites, chemerin may help to translate the signals of microbial insult to a host physiological response. Inactivation of chemerin in periodontal lesions might lead to the immune dysregulation. Alternatively, chemerin inactivation might represent a mechanism to suppress deleterious inflammation and bone loss that characterizes periodontitis.

\section{AUTHOR CONTRIBUTIONS}

Conceived and designed experiments: UG, PB, AS, SE, JP, and JC; performed the experiments: $\mathrm{UG}, \mathrm{PB}, \mathrm{AS}$, and ME; contributed reagents/materials: $\mathrm{PM}, \mathrm{BZ}, \mathrm{HJ}$, and $\mathrm{ME}$; wrote the paper: JC and BZ.

\section{FUNDING}

This work was supported by Polish National Science Center grant UMO 2014/12/W/NZ6/00454 (to JC). JP acknowledges partial support by grants from: NIH/NIDR (DE 023207 and DE 022597), the European Commission (FP7-HEALTH-F3-2012-306029 “TRIGGER”), National Science Center (UMO 2012/04/A/ NZ1/00051), and Polish Ministry of Science and Higher Education (project 2975/7.PR/13/2014/2). BZ was supported by Polish National Science Center grant UMO 2014/12/W/NZ6/00454. The Faculty of Biochemistry, Biophysics and Biotechnology of the Jagiellonian University is a beneficiary of the structural funds from the European Union (grant No: POIG.02.01.00-12064/08) and a partner of the Leading National Research Center (KNOW) supported by the Polish Ministry of Science and Higher Education.

\section{REFERENCES}

1. Zabel BA, Kwitniewski M, Banas M, Zabieglo K, Murzyn K, Cichy J. Chemerin regulation and role in host defense. Am J Clin Exp Immunol (2014) 3:1-19.

2. Wittamer V, Franssen JD, Vulcano M, Mirjolet JF, Le Poul E, Migeotte I, et al. Specific recruitment of antigen-presenting cells by chemerin, a novel processed ligand from human inflammatory fluids. J Exp Med (2003) 198:977-85. doi:10.1084/jem.20030382

3. Zabel BA, Silverio AM, Butcher EC. Chemokine-like receptor 1 expression and chemerin-directed chemotaxis distinguish plasmacytoid from myeloid dendritic cells in human blood. J Immunol (2005) 174:244-51. doi:10.4049/ jimmunol.174.1.244

4. Zabel BA, Allen SJ, Kulig P, Allen JA, Cichy J, Handel TM, et al. Chemerin activation by serine proteases of the coagulation, fibrinolytic, and inflammatory cascades. J Biol Chem (2005) 280:34661-6. doi:10.1074/jbc.M504868200

5. Kulig P, Zabel BA, Dubin G, Allen SJ, Ohyama T, Potempa J, et al. Staphylococcus aureus-derived staphopain $\mathrm{B}$, a potent cysteine protease activator of plasma chemerin. J Immunol (2007) 178:3713-20. doi:10.4049/jimmunol.178.6.3713

6. Kulig P, Kantyka T, Zabel BA, Banas M, Chyra A, Stefanska A, et al. Regulation of chemerin chemoattractant and antibacterial activity by human cysteine cathepsins. J Immunol (2011) 187:1403-10. doi:10.4049/jimmunol.1002352

7. Albanesi C, Scarponi C, Pallotta S, Daniele R, Bosisio D, Madonna S, et al. Chemerin expression marks early psoriatic skin lesions and correlates with plasmacytoid dendritic cell recruitment. JExp Med (2009) 206:249-58. doi:10.1084/jem.20080129

8. Luangsay S, Wittamer V, Bondue B, De Henau O, Rouger L, Brait M, et al. Mouse ChemR23 is expressed in dendritic cell subsets and macrophages, and mediates an anti-inflammatory activity of chemerin in a lung disease model. J Immunol (2009) 183:6489-99. doi:10.4049/jimmunol.0901037

9. Banas M, Zabieglo K, Kasetty G, Kapinska-Mrowiecka M, Borowczyk J, Drukala J, et al. Chemerin is an antimicrobial agent in human epidermis. PLoS One (2013) 8:e58709. doi:10.1371/journal.pone.0058709

10. Banas M, Zegar A, Kwitniewski M, Zabieglo K, Marczynska J, KapinskaMrowiecka M, et al. The expression and regulation of chemerin in the epidermis. PLoS One (2015) 10:e0117830. doi:10.1371/journal.pone.0117830

11. Maheshwari A, Kurundkar AR, Shaik SS, Kelly DR, Hartman Y, Zhang W, et al. Epithelial cells in fetal intestine produce chemerin to recruit macrophages. Am J Physiol Gastrointest Liver Physiol (2009) 297:G1-10. doi:10.1152/ ajpgi.90730.2008

12. Demoor T, Bracke KR, Dupont LL, Plantinga M, Bondue B, Roy MO, et al. The role of ChemR23 in the induction and resolution of cigarette smoke-induced inflammation. J Immunol (2011) 186:5457-67. doi:10.4049/ jimmunol.1003862
13. Ozcan E, Saygun NI, Serdar MA, Kurt N. Evaluation of the salivary levels of visfatin, chemerin, and progranulin in periodontal inflammation. Clin Oral Investig (2015) 19:921-8. doi:10.1007/s00784-014-1308-0

14. Patnaik K, Pradeep AR, Nagpal K, Karvekar S, Singh P, Raju A. Human chemerin correlation in gingival crevicular fluid and tear fluid as markers of inflammation in chronic periodontitis and type-2 diabetes mellitus. J Investig Clin Dent (2017) 8:e12181. doi:10.1111/jicd.12181

15. Hajishengallis G, Lamont RJ. Beyond the red complex and into more complexity: the polymicrobial synergy and dysbiosis (PSD) model of periodontal disease etiology. Mol Oral Microbiol (2012) 27:409-19. doi:10.1111/j.2041-1014.2012.00663.x

16. Jiao $\mathrm{Y}$, Hasegawa $\mathrm{M}$, Inohara $\mathrm{N}$. The role of oral pathobionts in dysbiosis during periodontitis development. JDent Res (2014) 93:539-46. doi: $10.1177 / 0022034514528212$

17. Dewhirst FE, Chen T, Izard J, Paster BJ, Tanner AC, Yu WH, et al. The human oral microbiome. J Bacteriol (2010) 192:5002-17. doi:10.1128/ JB.00542-10

18. Jenkinson HF. Beyond the oral microbiome. Environ Microbiol (2011) 13:3077-87. doi:10.1111/j.1462-2920.2011.02573.x

19. Socransky SS, Haffajee AD, Cugini MA, Smith C, Kent RL Jr. Microbial complexes in subgingival plaque. JClin Periodontol (1998) 25:134-44. doi:10.1111/j.1600-051X.1998.tb02419.x

20. Kolenbrander PE, Andersen RN, Blehert DS, Egland PG, Foster JS, Palmer RJ Jr. Communication among oral bacteria. Microbiol Mol Biol Rev (2002) 66:486-505, table of contents. doi:10.1128/MMBR.66.3.486-505.2002

21. Sharma A, Inagaki S, Sigurdson W, Kuramitsu HK. Synergy between Tannerella forsythia and Fusobacterium nucleatum in biofilm formation. Oral Microbiol Immunol (2005) 20:39-42. doi:10.1111/j.1399-302X.2004.00175.X

22. Nobbs AH, Jenkinson HF, Jakubovics NS. Stick to your gums: mechanisms of oral microbial adherence. JDent Res (2011) 90:1271-8. doi:10.1177/0022034511399096

23. Dale BA, Fredericks LP. Antimicrobial peptides in the oral environment: expression and function in health and disease. Curr Issues Mol Biol (2005) 7:119-33. doi:10.1093/jac/dki103

24. Gorr SU, Abdolhosseini M. Antimicrobial peptides and periodontal disease. JClin Periodontol (2011) 38(Suppl 11):126-41. doi:10.1111/j.1600-051X.2010.01664.x

25. Gorr SU. Antimicrobial peptides in periodontal innate defense. Front Oral Biol (2012) 15:84-98. doi:10.1159/000329673

26. Majchrzak-Gorecka M, Majewski P, Grygier B, Murzyn K, Cichy J. Secretory leukocyte protease inhibitor (SLPI), a multifunctional protein in the host defense response. Cytokine Growth Factor Rev (2016) 28:79-93. doi:10.1016/j. cytogfr.2015.12.001 
27. Majewski P, Majchrzak-Gorecka M, Grygier B, Skrzeczynska-Moncznik J, Osiecka O, Cichy J. Inhibitors of serine proteases in regulating the production and function of neutrophil extracellular traps. Front Immunol (2016) 7:261. doi:10.3389/fimmu.2016.00261

28. Bryksin AV, Matsumura I. Overlap extension PCR cloning: a simple and reliable way to create recombinant plasmids. Biotechniques (2010) 48:463-5. doi: $10.2144 / 000113418$

29. Zabieglo K, Majewski P, Majchrzak-Gorecka M, Wlodarczyk A, Grygier B, Zegar A, et al. The inhibitory effect of secretory leukocyte protease inhibitor (SLPI) on formation of neutrophil extracellular traps. J Leukoc Biol (2015) 98:99-106. doi:10.1189/jlb.4AB1114-543R

30. Guentsch A, Kramesberger M, Sroka A, Pfister W, Potempa J, Eick S. Comparison of gingival crevicular fluid sampling methods in patients with severe chronic periodontitis. J Periodontol (2011) 82:1051-60. doi:10.1902/ jop.2011.100565

31. Eick S, Straube A, Guentsch A, Pfister W, Jentsch H. Comparison of real-time polymerase chain reaction and DNA-strip technology in microbiological evaluation of periodontitis treatment. Diagn Microbiol Infect Dis (2011) 69:12-20. doi:10.1016/j.diagmicrobio.2010.08.017

32. Frohlich E, Kantyka T, Plaza K, Schmidt KH, Pfister W, Potempa J, et al. Benzamidine derivatives inhibit the virulence of Porphyromonas gingivalis. Mol Oral Microbiol (2013) 28:192-203. doi:10.1111/omi.12015

33. Shen Y, Li Y, Ye F, Wang F, Lu W, Xie X. Identification of suitable reference genes for measurement of gene expression in human cervical tissues. Anal Biochem (2010) 405:224-9. doi:10.1016/j.ab.2010.06.029

34. Livak KJ, Schmittgen TD. Analysis of relative gene expression data using realtime quantitative PCR and the 2(-Delta Delta C(T)) Method. Methods (2001) 25:402-8. doi:10.1006/meth.2001.1262

35. Ouhara K, Komatsuzawa H, Yamada S, Shiba H, Fujiwara T, Ohara M, et al. Susceptibilities of periodontopathogenic and cariogenic bacteria to antibacterial peptides, \{beta\}-defensins and LL37, produced by human epithelial cells. J Antimicrob Chemother (2005) 55:888-96. doi:10.1093/jac/dki103

36. Kadowaki T, Baba A, Abe N, Takii R, Hashimoto M, Tsukuba T, et al. Suppression of pathogenicity of Porphyromonas gingivalis by newly developed gingipain inhibitors. Mol Pharmacol (2004) 66:1599-606. doi:10.1124/ mol.104.004366

37. Gemmell E, Mchugh GB, Grieco DA, Seymour GJ. Costimulatory molecules in human periodontal disease tissues. J Periodontal Res (2001) 36:92-100. doi:10.1034/j.1600-0765.2001.360205.x

38. Berglundh T, Donati M. Aspects of adaptive host response in periodontitis. J Clin Periodontol(2005)32(Suppl6):87-107.doi:10.1111/j.1600-051X.2005.00820.x
39. Cekici A, Kantarci A, Hasturk H, Van Dyke TE. Inflammatory and immune pathways in the pathogenesis of periodontal disease. Periodontol (2014) 2000(64):57-80. doi:10.1111/prd.12002

40. Wilensky A, Chaushu S, Shapira L. The role of natural killer cells in periodontitis. Periodontol (2015) 2000(69):128-41. doi:10.1111/prd.12092

41. Lam RS, O’Brien-Simpson NM, Holden JA, Lenzo JC, Fong SB, Reynolds EC. Unprimed, M1 and M2 macrophages differentially interact with Porphyromonas gingivalis. PLoS One (2016) 11:e0158629. doi:10.1371/journal. pone.0158629

42. Saiki K, Konishi K. Identification of a Porphyromonas gingivalis novel protein sov required for the secretion of gingipains. Microbiol Immunol (2007) 51:483-91. doi:10.1111/j.1348-0421.2007.tb03936.x

43. Griffen AL, Beall CJ, Campbell JH, Firestone ND, Kumar PS, Yang ZK, et al. Distinct and complex bacterial profiles in human periodontitis and health revealed by $16 \mathrm{~S}$ pyrosequencing. ISME J (2012) 6:1176-85. doi:10.1038/ ismej.2011.191

44. Wang J, Qi J, Zhao H, He S, Zhang Y, Wei S, et al. Metagenomic sequencing reveals microbiota and its functional potential associated with periodontal disease. Sci Rep (2013) 3:1843. doi:10.1038/srep01843

45. Levy O. Antimicrobial proteins and peptides of blood: templates for novel antimicrobial agents. Blood (2000) 96:2664-72.

46. Muruganandan S, Roman AA, Sinal CJ. Role of chemerin/CMKLR1 signaling in adipogenesis and osteoblastogenesis of bone marrow stem cells. J Bone Miner Res (2010) 25:222-34. doi:10.1359/jbmr.091106

47. Liu YC, Lerner UH, Teng YT. Cytokine responses against periodontal infection: protective and destructive roles. Periodontol (2010) 2000(52):163-206. doi:10.1111/j.1600-0757.2009.00321.x

Conflict of Interest Statement: The authors declare that the research was conducted in the absence of any commercial or financial relationships that could be construed as a potential conflict of interest.

Copyright (c) 2017 Godlewska, Brzoza, Sroka, Majewski, Jentsch, Eckert, Eick, Potempa, Zabel and Cichy. This is an open-access article distributed under the terms of the Creative Commons Attribution License (CC BY). The use, distribution or reproduction in other forums is permitted, provided the original author(s) or licensor are credited and that the original publication in this journal is cited, in accordance with accepted academic practice. No use, distribution or reproduction is permitted which does not comply with these terms. 